\title{
1 Hominoid arcade shape: pattern and magnitude of covariation
}

2

3

4 Stefanie Stelzer ${ }^{1}$, Philipp Gunz ${ }^{1}$, Simon Neubauer ${ }^{1}$, Fred Spoor $^{1,2}$

5

$6{ }^{1}$ Department of Human Evolution, Max Planck Institute for Evolutionary Anthropology, Leipzig 04103,

7 Germany.

$8{ }^{2}$ Department of Cell and Developmental Biology, University College London, London WC1E 6BT, UK.

21 Keywords: maxilla, mandible, premaxilla, integration, jaw, canine

23 Correspondence: Stefanie Stelzer, Max Planck Institute for Evolutionary Anthropology, Department of

24 Human Evolution, Deutscher Platz 6, 04103 Leipzig, Germany. E-mail: stefanie_stelzer@eva.mpg.de 


\section{Abstract}

The shape of the dental arcade and canine size distinguish extant humans from all apes.

27 Humans are characterized by a parabolic arcade with short postcanine tooth rows and small canines,

28 whereas apes have long, U-shaped arcades with large canines. The evolutionary and biomechanical

29 mechanisms underlying arcade shape differences between and within groups are not well understood. It

30 is unclear, for example, whether evolutionary changes in the covariation among modules comprising the

31 upper and lower jaws are the cause and/or consequence of different arcade shapes. Here we use 3D

32 geometric morphometric methods to explore to what extent the morphological differences in arcade

33 shape between living hominoids are related to differences in covariation of upper and lower jaws, and

34 the premaxilla and the maxilla. We show that all extant hominoids follow a very similar covariation

35 pattern between upper and lower dental arcades, as well as between the premaxilla and the maxilla. We

36 find comparably high magnitudes of covariation between the premaxilla and the maxilla in all groups.

37 Between the upper and lower jaws, levels of covariation are similar in apes (Pan, Gorilla, Pongo, and

38 Hylobates), but overall lower in extant humans. Our results demonstrate an independence of the

39 pattern of arcade shape covariation from dental spatial arrangements. Importantly, we show that a

40 shared hominoid pattern of covariation between premaxilla and maxilla together with the covariation of

41 upper and lower jaw is consistent with major evolutionary arcade shape changes in hominoids. We

42 suggest that with the reduction of canine and diastema size in hominins, the incisors move posteriorly

43 and the tooth row becomes more parabolic. Our study provides a framework for addressing questions

44 about fossil hominin dentognathic diversity, including inter- and intraspecific variation and associations

45 of upper and lower jaw morphology. 
Dentognathic morphology of extant humans and apes differs notably in canine size and arcade

49 shape. In apes, the arcades are U-shaped with narrow and near-parallel postcanine tooth rows.

50 Furthermore, dental arcade shape varies within and between ape species: posteriorly diverging or

51 converging postcanine tooth rows result in a range of arcade contours (Hellman, 1919). In some

52 individuals the arcade tapers in the premolar region to diverge again more posteriorly, giving it a saddle

53 shape (Hellman, 1919; Remane, 1921). The large lower canines are accommodated in a diastema

54 between the upper lateral incisor and the enlarged upper canine; in the mandible, the upper canine is

55 accommodated between the lower canine and the lower premolars (Angle, 1899; Hellman, 1942), where

56 canine size can vary strongly inter- and intraspecifically (Almquist, 1974; Leutenegger and Kelly, 1977;

57 Oxnard et al., 1985; Leutenegger and Shell, 1987; Plavcan and van Schaik, 1992; Plavcan, 1993; Kelley,

58 1995).

59 Modern human dental arcades are usually referred to as being parabolic (Angle, 1899; Broomell,

60 1902; Le Gros Clark, 1950; Genet-Varcin, 1969), elliptic (Black, 1902; Garn, 1968; Currier, 1969; Brader,

61 1972) or catenary (MacConaill and Scher, 1949; Scott, 1957; Engel, 1979), with upper and lower arcades

62 having slightly different shapes (Hellman, 1919; Engel, 1979). Incisors and canines are of almost equal

63 size (Schwartz, 1995) and their occlusal surfaces are on the same level as the postcanine dentition.

Intra- and interspecific differences in cranial and mandibular architecture among primates have

65 been related to differences in masticatory behavior, including varying mechanical stress (Hrdlicka, 1940;

66 Hylander, 1972; Carlson and Vangerven, 1977; Hylander, 1979; Weijs and Hillen, 1984; Bouvier, 1986;

67 Weijs and Hillen, 1986; Armelagos et al., 1989; Ravosa, 1990; Corruccini, 1991; Herring, 1993; Anapol

68 and Lee, 1994; Larsen, 1995; Cassidy et al., 1998; Sardi et al., 2004; Lieberman, 2008; von Cramon-

69 Taubadel, 2011; Prasad et al., 2013). These biomechanical arguments emphasize that relative position 
and length of the dental arcade influence the stress distribution (Witzel and Preuschoft, 2002). In this

71 view, phenotypic variation of the upper and lower jaw is seen as a consequence rather than a

72 precondition for different force distributions. In apes relatively long tooth rows and prognathic dental

73 arcades seem to be biomechanically advantageous, whereas in humans the parabolic arcade is seen as a

74 side effect of reduction in bite- and chewing forces and the reorganization of the face (Preuschoft, 1989;

75 Witzel and Preuschoft, 1999) with little biomechanical significance (Preuschoft and Witzel, 2004). Recent

76 studies in capuchin monkeys (Makedonska et al., 2012) and modern humans (Noback and Harvati, 2015)

77 showed that, at least within groups, dental arcade shape (in contrast to size and position) is largely

78 independent from masticatory forces. These authors found correlations between diet and shape of the

79 temporalis muscle and the cranium, but none between subsistence and maxillary arch shape.

The evolutionary and biomechanical mechanisms underlying the differences in arcade shape

81 between extant humans and apes, as well as those underlying the within-group variability, are not well

82 understood. The evolutionary trajectory of our lineage is interesting in this regard, as arcade shape

83 varies considerably among fossil hominins (e.g., Weidenreich, 1936; Tobias, 1967; Johanson et al., 1978;

84 Johanson and White, 1979; Greenfield, 1992). Besides a general reduction in absolute canine size, early

85 hominins like Australopithecus anamensis and A. afarensis possess primitive features such as a small

86 diastema between the upper incisor and the canine, as well as parallel to slightly diverging tooth rows

87 (Schwartz, 1995; White et al., 2000; Ward et al., 2001; Kimbel and Delezene, 2009). Some early Homo

88 specimens retain long and almost parallel tooth rows, whereas others have shorter postcanine rows and

89 non-projecting frontal tooth rows (Tobias, 1991; Wood, 1991; Rightmire, 1993; Kimbel et al., 1997;

90 Clarke, 2012; Leakey et al., 2012; Spoor et al., 2015). Large-scale differences in jaw shapes have been

91 used to support arguments about species diversity in early Homo (Spoor et al., 2015). Moreover, it has

92 been argued that high variation in the anterior maxillary region, the premaxilla, indicates that it might

93 have been subject to selection in hominin evolution (Villmoare et al., 2014). Understanding the 
94 mechanisms contributing to the variation and covariation of jaw shapes in extant hominoids is thus

95 informative for interpreting the hominin fossil record.

96 Morphological covariation is the statistical interrelationship of morphometric variables

97 (Mitteroecker and Bookstein, 2007). It is the consequence of developmental, evolutionary, genetic, and

98 functional processes (Cheverud, 1996a) that in combination lead to integration of structures. Integrated

99 traits must covary, however, traits that covary are not necessarily integrated (Villmoare et al., 2014).

100 Although not equivalent (compare Porto et al., 2009; Young et al., 2010; Grabowski et al., 2011),

101 integration and covariation are mutually dependent in that covarying structures influence the way an

102 organism can react to evolutionary forces. On the other hand, evolution can also act on the covariation

103 of structures. Using 3D geometric morphometric methods we explore the pattern and magnitude of the

104 covariation between and within upper and lower arcades in extant hominoids. We seek to understand if

105 and how the morphological differences in arcade shape between living hominoids are related to

106 differences in covariation of upper and lower jaws.

107 Previous studies of cranial integration and covariation have consistently demonstrated

108 conserved patterns among primates and even mammals (Cheverud, 1996b; Ackermann and Cheverud,

109 2000; Lieberman et al., 2000; Marroig and Cheverud, 2001; Ackermann, 2002; Gonzalez-Jose et al.,

110 2004; Marroig et al., 2004; Ackermann, 2005; Goswami, 2006; Gunz and Harvati, 2007; Mitteroecker and

111 Bookstein, 2008; Porto et al., 2009; Makedonska et al., 2012; Villmoare et al., 2014). In this study we

112 assess (1) whether the same applies to hominoid upper and lower dental arcades, or (2) whether the

113 variation in extant arcade shapes is associated with a variation of the underlying patterns of covariation.

114 The magnitude of covariation has been related to material properties of food, in that taxa

115 relying on a mechanically challenging diet have stronger integrated upper and lower jaws (Marroig and

116 Cheverud, 2001; Makedonska et al., 2012). Pan, Pongo, Gorilla, and Hylobates consume different 
117 proportions of leaves, fruit, other plant parts, or insects, and their dietary preferences are dependent on

118 season, food availability, habitat and sex. In general, however, Pan, Pongo, and Hylobates are more

119 frugivorous, whereas Gorilla is more reliant on leaves (MacKinnon, 1974; Rijksen, 1978; Gittins and

120 Raemaekers, 1980; Watts, 1984; Galdikas, 1988; Tutin and Fernandez, 1993; Knott, 1998; McConkey et

121 al., 2003; Rogers et al., 2004; Boesch et al., 2006; Doran-Sheehy et al., 2009). Morphologically, this

122 difference is reflected in relative dental sizes. Frugivores have relatively larger incisors, while foliovores

123 have relatively larger molars (Hylander, 1975; Kay and Hylander, 1978). In comparison to apes, modern

124 humans have a more generalist diet, where extra-oral food processing via tool use or cooking is thought

125 to have reduced the masticatory effort since the emergence of our species or even earlier (e.g. Brace et

126 al., 1987; Wrangham et al., 1999; Richards et al., 2001; Teaford et al., 2002; Henry, 2010). While a

127 correlation with diet seems likely, some authors have suggested that the lower covariation magnitudes

128 in the human cranium (Marroig et al., 2009; Porto et al., 2009) and pelvis (Grabowski et al., 2011) may

129 indicate a general relaxation of integration in the hominin lineage. These authors argued that the

130 change in magnitude of integration might have paved the way for the development of the

131 morphological changes characterizing our lineage. In addition to the two aforementioned aims, we

132 therefore also assess (3) whether there are differences in the magnitude of covariation between the

133 groups, and (4) whether there are differences between females and males within groups.

It has been argued that within the maxilla, the premaxilla represents its own module that has

135 been a target of selection in the hominin lineage leading to higher variation in the anterior region in

136 hominins compared to other anthropoids (Villmoare et al., 2014). The reduction of canine and thereby

137 diastema size is associated with an earlier closure of the premaxillary sutures (McCollum and Ward,

138 1997; Braga, 1998). We explore whether those differences are associated with a change in the pattern

139 or the magnitudes of covariation. We therefore also assess (5) the pattern and magnitudes of

140 covariation between the premaxilla and the maxilla. 


\section{Materials and methods}

\section{Samples}

Our samples are summarized in Table 1 and in the Supplementary Online Material (SOM) Table

145 S1. The modern human sample $(n=53)$ comprises geographically diverse pre-industrial populations, and

146 was obtained from the Institute of Anatomy at Leipzig University (ULAC), Germany; the Natural History

147 Museum London, UK; the National Historical Museum, Buenos Aires, Argentina; the American Museum

148 of Natural History, New York; and the Smithsonian Institution, Washington, D.C., USA. The Pan

149 troglodytes sample $(n=44)$ is comprised of specimens from Côte d'Ivoire, Liberia, Gabon, Cameroon and

150 Equatorial Guinea, housed at the Senckenberg Museum, Frankfurt, Germany; at the Max Planck Institute

151 for Evolutionary Anthropology in Leipzig (MPI-EVA), Germany; the Phyletisches Museum, Jena,

152 Germany; and the Smithsonian Institution; plus one zoo specimen housed in the Phyletisches Museum

153 Jena. The Gorilla sample ( $n=53$ ) includes Gorilla gorilla specimens from Cameroon, Gabon, and the

154 Congo, and Gorilla beringei from Rwanda, housed at the Museum für Naturkunde Berlin, Germany; the

155 Phyletisches Museum, Jena and the Smithsonian Institution. The Pongo sample $(n=52)$ comprises $P$.

156 pygmaeus and $P$. abelii specimens from Borneo and Sumatra, respectively, and one specimen with

157 unknown provenance. The Pongo specimens are housed at the Museum für Naturkunde Berlin and the

158 Smithsonian Institution. The Hylobates specimens ( $n=63$ ) include the species $H$. agilis (Sumatra), $H$.

159 albibarbis (Borneo), H. klossii (Sumatra), H. lar (Thailand, Myanmar), and H. muelleri (Borneo). The

160 specimens are housed at the Museum für Naturkunde Berlin and the Smithsonian Institution. Sex

161 attributions were taken from museum records when available. Sex of the remaining specimens of Pan,

162 Gorilla and Pongo was determined by several observers based on the formation of cranial

163 superstructures and canine size. 
We used computed tomography (CT) of all specimens, including both industrial CT (BIR ACTIS

165 225/300 at the Max Planck Institute for Evolutionary Anthropology, Leipzig, Germany; isotropic voxel

166 sizes $0.03-0.093 \mathrm{~mm}$ ) and medical CT (Vivantes Klinikum Berlin, Germany; CIMED, La Plata, Argentina;

167 the Senckenberg Museum, and the Smithsonian Institution, Washington, U.S.A. (modern human CT

168 scans obtained as part of Copes (2012)); pixel sizes $0.13-0.47 \mathrm{~mm}$, slice intervals $0.33-0.50 \mathrm{~mm}$ ). Our

169 sample comprises scans of adult individuals (defined as third molars in occlusion) that preserved both

170 cranium and mandible and did not display malocclusions or other severe pathologies. So as to achieve

171 comparably large sample sizes for all groups that meet these strict criteria, we pooled the respective

172 species of Gorilla, Pongo, and Hylobates in our analyses. Species specific morphologies within genera are

173 known (e.g. Groves, 1970, 1972; Rörer-Ertl, 1984; Uchida, 1998; Guy et al., 2003; Schmittbuhl et al.,

174 2007, but see Groves et al. 1992; Courtenay et al. 1998 for a different view on Pongo), however, the

175 differences in dental arcade shape seem to be negligible, when compared to the shape differences

176 between genera, as can be seen in SOM Figures S1-S3, in which the species of each individual are color

177 coded to illustrate that they are randomly scattered within the convex hulls of their respective genera.

179 Data

The occlusal surfaces of teeth are modified by wear, which makes placing homologous

181 landmarks problematic. Hence, we took landmarks on the alveolar margin of every tooth and on the

182 cervix of the postcanine dentition in order to capture arcade shape, spatial arrangement of the teeth,

183 and dental size proportions. We recorded 224 homologous 3D landmarks on the mandibular and the

184 maxillary dental arcades (112 landmarks each) (Fig. 1). All measurements were taken in Avizo 7.1

185 (Visualization Sciences Group). 
To capture overall length and breadth patterns, landmarks were placed on the distal, buccal,

187 mesial and lingual surfaces of the incisor, canine and premolar alveolus. On the molars, besides a distal

188 and a mesial landmark, we set two landmarks buccally and two lingually at the position of each root. On

189 the third molar we took one landmark buccally and lingually at the position of the mesial root. The

190 cervical landmarks were positioned distally, buccally, mesially, and lingually.

- Table 1 -

Analysis

Landmarks on the upper and the lower jaw were superimposed separately applying Generalized

Procrustes Analysis (GPA) to extract shape information independent from rotation, translation and

the Procrustes shape coordinates for mandibles and maxillae separately to assess taxonomic shape 198 differences.

Landmarks on the premaxilla (incisors) and the maxilla (canines, premolars, and molars) were superimposed together to retain information on the exact position of the premaxilla relative to the 201 maxilla. In the analysis of the covariation between premaxilla and maxilla, only the alveolar, not the 202 cervical, landmarks were used to capture the morphology of the postcanine dentition.

204 covariation of the mandibular and the maxillary arcade shape, or the premaxilla and the maxilla,

205 respectively (Rohlf and Corti, 2000; Bookstein et al., 2003). We used the mean of the original data and

206 the reflected relabeled landmark configuration in order to symmetrize the data and therewith remove

207 asymmetric shape variation that also arises from asymmetric measurement error (Klingenberg and

208 McIntyre, 1998; Mardia et al., 2000; Mitteroecker and Gunz, 2009). The PLS analysis computes 
correlated pairs of vectors, so-called singular warps (SW), for the maxilla and for the mandible, or the

210 premaxilla and the maxilla, respectively, that account for the maximum covariance between the two

211 sets of landmarks (Wold, 1966; Rohlf and Corti, 2000; Bookstein et al., 2003).

We performed two PLS analyses per data set: one includes all groups with the data mean

213 centered for each group. This explores the overall pattern of covariation while accounting for large-scale

214 differences between the groups. The second PLS analysis was performed for every group separately,

215 mean centered by sex. If all groups follow a similar pattern of covariation, shape variation associated

216 with PLS axes of the pooled sample and within groups should be similar.

217 Magnitude of covariation We used two metrics to quantify the magnitude of covariation; the

218 covariance ratio (CR, Adams, 2016) and the correlation coefficient between the singular warp scores

219 (Bookstein et al., 2003). The CR has been proposed recently by Adams (2016) as an alternative to the RV

220 coefficient that overcomes some of the fundamental methodological issues associated with the RV

221 coefficient (Smilde et al., 2009; Fruciano et al., 2013; Bookstein, 2016). The CR quantifies the overall

222 pattern of covariation between the blocks. Therefore one does not know which aspect of covariation the

$223 \mathrm{CR}$ is quantifying. In contrast, the correlations of the singular warp scores pertain to the pattern

224 visualized in the respective singular warp plots, and are easier to interpret. As our sample sizes are not

225 equal across all groups, we used a resampling approach for computing the values for the CR. To get a

226 representative distribution, the CR was calculated for 30 randomly selected individuals in 1000 iterations

227 per group.

A permutation test (Good, 2000) was used to determine the significance of the mean

229 differences between the permutated CR values (Bonferroni-corrected for multiple testing, considered

230 significant at $\alpha<0.05)$. 
232 the mean shape differences between male and female mandibles and maxillae. To do so, we randomly

233 selected individuals and assigned them to male or female and computed a mean shape and shape

234 difference between the permuted sexes 10000 times (considered significant at $\alpha<0.05$ ).

Allometry To assess the amount of the total shape variance that can be explained by jaw size we

236 separately computed multivariate regressions of upper and lower arcade shapes on the natural

237 logarithms of their centroid sizes. We evaluated the statistical significance of these regressions using a

238 permutation test based on the explained variance (Mitteroecker et al., 2013).

Intra-observer error All data were measured by one of the authors (S.S). Intra-observer error

240 was assessed by an analysis of repeated measurements: one specimen (Gorilla gorilla, ZMB 14645,

241 medical CT scan, voxel size $0.227 \times 0.227 \times 0.335 \mathrm{~mm}$ ) was measured fifteen times. The largest Procrustes

242 distance between repeated measurements of this individual was considerably smaller than the smallest

243 Procrustes distance between different specimens of the same species. Specimen affinity is therefore not

244 affected by intra-observer error.

245 All analyses and visualizations were performed in Mathematica 8.0 (Wolfram Research Inc., 2010).

247 Results

248 1. $P C A$

Table 2 shows the results of the principal components (PC) analysis. The first PC (PC1, 66.9\% of

250 total shape variance in maxillae, $70.8 \%$ in mandibles) separates humans from the other groups. Both,

251 maxillae (Fig. 2a) and mandibles (Fig. 2c), have short parabolic arcades and small canines on the positive

252 end (humans) compared to a U-shaped arch, long parallel tooth rows with large canines on the negative

253 side (apes). 
255 relatively large postcanine dentition with relatively small incisors in the positive direction (Gorilla); and 256 relatively large incisors with a relatively small postcanine dentition in the negative direction (Pan) (Fig.

257 2a). For the mandibles (10.9\% of the total shape variance), PC2 combines a long postcanine tooth row

258 with small incisors on the positive end (Gorilla), whereas the negative extreme of PC2 combines a short 259 postcanine tooth row with a large anterior dentition (Pan) (Fig. 2c).

261 other hominoids. For the maxilla in the negative direction, relatively small postcanine teeth are

262 accompanied by relatively large canines and small incisors; the arcade is slightly V-shaped (Hylobates)

263 (Fig. 2b). For the mandibles, moderately sized canines are associated with relatively large postcanine

264 teeth and incisors in the positive direction of PC3 (other groups). The lower scores of PC3 describe

265 relatively small postcanine dentition associated with relatively small incisors and slightly enlarged 266 canines (Hylobates).

\section{Pattern and magnitudes of covariation between the upper and the lower arcades}

271 explained covariance for the first five PLS components. On the positive side of PLS1 $(61.4 \%$ of the total

272 covariance, $r=0.73$ ), parabolic mandibles are associated with parabolic maxillae. On the negative side,

273 maxillary and mandibular arcades are U-shaped (Fig. 3a). Humans have positive PLS1 scores and are

274 separated from the apes that have decreasing scores along a diagonal line, starting at chimpanzees, to

275 gibbons, orang-utans and then gorillas. 
At the negative extreme of PLS2 (21.6\% of the total covariance, $r=0.81)$ large maxillary canines

277 are associated with large mandibular canines. The postcanine dentition is relatively small, short and

278 parallel. At the positive extreme, small mandibular canines and V-shaped arcades are associated with

279 small maxillary canines and arcades that are more rounded than the mandibles (Fig. 3b). Humans have

280 positive PLS2 scores and are separated from the apes along a diagonal line.

At the negative end of PLS3 (7.9\% of the total covariance, $r=0.73)$, both arcades are broad and groups along the PLS3 axis is less clear. specimens are shifted away from the hominid trajectory, but their trajectory has the same slope.

292 the explained covariance for the first five PLS components for each group. At the positive end of PLS1, in 293 all groups, rounded maxillae are associated with broad and rounded mandibles (Fig. 4 a-e). In the apes,

294 the maxillary arcade is anteriorly wider than the mandibular arcade. At the negative end of PLS1, long 295 and straight postcanine maxillary arcades are associated with straight mandibular postcanine arcades 296 that taper slightly in the premolar region. In Hylobates, PLS1 and PLS2 are interchanged, so that the 297 aforementioned shape changes are described by PLS2 (SOM Fig. S4). In addition, the maxillary arcade in 298 Hylobates also tapers in the premolar region. The anterior regions in both upper and lower arcades are 
rounded and extend anteriorly. PLS scores of PLS2 and PLS3 and wireframes of the first three PLS

300 components are shown in SOM Figs. S4 and S5.

301

At the positive end of PLS2 in all groups, straight diverging posterior maxillary arcades are

302 associated with likewise diverging mandibular arcades. At the negative end of PLS2, straight converging

303 posterior maxillary tooth rows are associated with mandibular tooth rows that behave similarly. These

304 shape changes are described by PLS1 in Hylobates. In addition, on the positive side of this PLS

305 component, Hylobates is more straight than converging. In Homo, PLS2 and PLS3 are interchanged. The

306 incisal part of the upper and lower arcades in all groups are flat, with the exception of Homo and

307 Hylobates, where the mandibular arcades are more rounded anteriorly (SOM Figs. S4 and S5).

At the negative end of PLS3 in all groups, straight posterior tooth rows and flat anterior teeth in

309 the maxilla are associated with likewise shaped mandibular arcades. In Pan, Gorilla and Pongo, the

310 postcanine tooth rows are parallel, in Homo and Hylobates the arcades diverge in both upper and lower

311 jaws. At the positive end of PLS3, anteriorly extending incisors and large diastemata in the maxilla are

312 associated with long straight mandibular arcades, where the incisors extend anteriorly as well. In Homo

313 both arcades are more rounded in the postcanine row and less pointed in the anterior region (SOM Figs.

314 S4 and S5).

315 Overall, all groups show similar covariation patterns.

318 blocks The associated shape (co)variation between the maxillary arcades and the mandibular arcades

319 along PLS1 and PLS2 is comparable to the shape variation within the maxillae and within the mandibles

320 along PC1 (i.e.. parabolic arcades with small canines versus long U-shaped arcades with large canines). 
321 Also the shape changes along PLS3 are partly represented by the variation described by PC3 (broad

322 versus V-shaped arcades).

323

Magnitude of covariation (all groups combined) Results for the covariance ratio (CR) are given

325 in Table 4. The distribution of values for the permutated CRs from varied sample composition is shown

326 in Fig. 5. The apes overlap completely with CRs varying from 0.71 to 0.89 . Homo shows values between

3270.64 and 0.89. Median values are 0.81 (Pongo), 0.81 (Pan), 0.80 (Gorilla), 0.81 (Hylobates), and 0.76

328 (Homo). Homo is significantly different from every other group ( $p<0.02$, Bonferroni corrected). Pan,

329 Gorilla, Pongo, and Hylobates are not significantly different from each other ( $p>0.12$ at least) (Table 4).

330 The correlation coefficient of PLS1 is lowest in Gorilla, followed by Homo, Pongo, and Pan.

331 Hylobates show the highest value (Table 5). The correlation coefficient of PLS2 is lowest in Hylobates,

332 followed by Homo. Pan, Pongo, and Gorilla show higher values. In PLS3, the correlation coefficient is

333 lowest in Hylobates and Homo. Gorilla falls between the latter two and Pongo and Pan.

338 number of subsamples (female Homo) minus one, and considered the bootstrapping distribution

339 resulting from 1000 iterations for the calculation of the CR (Table 6). Correlation coefficients are given in 340 Table 7. 
342 than their male conspecifics (SOM Fig. S6) in the CR. In Hylobates, however, the males show higher 343 values.

345 counterparts. Hylobates show the opposite pattern, so do male Pan even though the difference from

346 the females is small. In PLS2 male Pan, Gorilla, and Homo show higher values than the females. Pongo,

347 Homo, and Hylobates show the opposite pattern. In PLS3 males show higher values than females in all 348 groups.

For the maxillary arcades, size explains $14.3 \%$ of the total variance in Gorilla, $12.6 \%$ in Pongo, $3536.8 \%$ in Pan, $2.5 \%$ in Homo, and $2.4 \%$ in Hylobates $(p<0.01)$. For the mandibular arcades size explains $3548.5 \%$ of the total variance in Gorilla, $9.7 \%$ in Pongo, $4.8 \%$ in Pan, $2.4 \%$ in Homo, and 3.6\% in Hylobates $355(p<0.01)$ (Table 8).

\section{Sexual dimorphism} Mean arcade shapes of female and males differ significantly (all $p$-values smaller than 0.05 ) in

359 Gorilla, Pan and Pongo. While the mandible shapes of female and male Homo sapiens are not

360 statistically different, the maxillae fall just below the significance level ( $p=0.047)$. There is no significant

361 shape difference between female and male Hylobates (Fig. 6). 
The main difference between male and female great apes is basal crown area of the canine. In

363 Pongo and Gorilla, this is associated with small differences in the anterior region. In females, the incisors

364 are shifted slightly posteriorly. In the postcanine dentition, the premolars are shifted anteriorly, whereas

365 the molar region remains unaffected. In humans, the subtle difference is also canine crown area.

- Figure 6 -

5. Pattern and magnitudes of covariation between the premaxilla and the maxilla

explained covariance for the first five PLS dimensions. In PLS1 (84.1\% of the total covariance, $r=0.96)$,

370 all groups scatter along a diagonal (Fig. 7a). At the negative end of PLS1 (gorillas followed by the other

371 non-human apes) large incisors are placed far anteriorly, creating a diastema between the maxilla and

372 the premaxilla. The posterior dentition is parallel, and canines are large. At the positive end (humans),

373 incisors and canines are small and incorporated in the dental arcade, and the posterior arcade is 374 parabolic (Fig. 7a).

In PLS2 (10.2\% of the total covariance, $r=0.59)$, the groups still cluster along the diagonal, but

376 are shifted parallel from each other with large overlap among groups (Fig.7b). At the negative end of

377 PLS2, large spaciously arranged incisors are associated with rounded posterior arcades and there is no

378 diastema. At the positive end of PLS2, smaller incisors are positioned in closer proximity and are placed

379 anteriorly followed by a diastema and the posterior dentition is straight and parallel (Fig. 7b).

- Figure 7-

- Table 9 explained covariance for the first five PLS components for each group separately. SOM Figure S7 shows 384 the PLS scores for every group in the first three PLS dimensions. 
At the negative end of PLS1 for every group, anteriorly expanding incisors are associated with

386 straight, parallel posterior tooth rows. In Pan, Gorilla, and Pongo, diastemata are present. At the

387 positive end there are no diastemata between the premaxillae and the maxillae. The incisors are

388 incorporated in the dental arcade. The posterior row is more rounded (SOM Fig. S8, top row).

In the negative direction of PLS2, rather flat anterior regions are associated with wide, more

390 rounded posterior arcades. At the positive end, the incisal region extends anteriorly, creating a diastema

391 between the premaxilla and the maxilla. The posterior arcade is straight. Gorilla differs in showing

392 straight posterior arcades in both directions; Homo shows no diastema and the posterior arcades are

393 parabolic in both directions (SOM Fig. S8, middle row).

PLS3 describes the spacing of the incisors. In the negative direction, incisors are narrowly

395 positioned. In the positive direction, incisors are widely spaced (SOM Fig. S8, bottom row).

The associated shape changes along all three PLS dimensions in the separate PLS analysis correspond to the shape changes observed in the combined analysis.

Magnitudes of covariation (all groups) Magnitudes of covariation (covariance ratio) are slightly

400 smaller between the premaxilla and the maxilla than between the upper arcade and the lower arcade in

401 the apes (Fig. 8, Table 10). In Homo, the values are comparable.

Gorilla is significantly different from Homo and Hylobates ( $p<0.015$, Bonferroni corrected), but

403 not from Pongo. The difference between Gorilla and Pan is close to the significance level $(p \leq 0.0559)$.

404 Pan, Pongo, Homo, and Hylobates are not significantly different from each other ( $p>0.27$ at least) (Table 405 10).

The correlation coefficient in PLS1 is lowest in Pan and Hylobates, followed by Pongo, Homo and 407 Gorilla (Table 11). In PLS2, the correlation coefficient is lowest in Gorilla, followed by Pongo. Homo and 
Hylobates show similar values. Pan shows the highest correlation coefficient. In PLS3, Gorilla shows the

409 highest value, followed by Pongo, Pan, and Hylobates. Homo shows the lowest correlation coefficient.

414 number of subsamples (female Homo) minus one, and considered the bootstrapping distribution

415 resulting from 1000 iterations for the calculation of the CR (SOM Table S2). Correlation coefficients are 416 given in SOM Table S3.

Pan and Gorilla show a marked sexual dimorphism with females showing lower values than

418 males in the covariance ratio (SOM Table S2). In Pongo, Homo, and Hylobates, male and female

419 distributions overlap. In all groups, magnitudes of covariation are in general slightly smaller between the

420 premaxilla and the maxilla than between the upper and the lower arcades. Only male Gorilla show

421 higher magnitudes (SOM Fig. S9).

423 counterparts. Homo shows the opposite pattern, in Pongo values are similar (SOM Table S3). In PLS2

424 male Pan, Gorilla, and Pongo show higher values than females. In Homo and Hylobates the opposite is

425 true. In PLS3 correlation coefficients are low in all groups except for Pan, where males show higher

426 values than females.

428 Discussion 
In this study we sought to explore the pattern and magnitude of the covariation between the

430 upper and the lower jaw, as well as between the premaxilla and the maxilla in extant hominoids. In the

431 first three PLS components, that together explain more than $90 \%$ of the total covariance of the upper

432 and the lower arcade, the data points scatter along the diagonal (Fig. 3). Such an arrangement is

433 interpreted as the same pattern of covariation (e.g. Mitteroecker and Bookstein, 2008). While retaining

434 the same slope, Hylobates are shifted from the hominid trajectory in PLS2 (Fig. 3b), probably owing to

435 the presence of absolutely and relatively large canines in males and females in this group.

We also performed separate PLS analyses which showed that the related shape changes of the

437 mandibular and the maxillary arcades are similar across species (Fig. 4 and SOM Figs. S4 and S5). In

438 general, this result suggests a common hominoid pattern of covariation and that the evolutionary shape

439 changes that led to hominoid arcade variation are not associated with modification of the underlying

440 covariation of arcades. Importantly, our data demonstrate an independence of the pattern of

441 covariation, which is similar in the analyzed species, from dental spatial arrangements, which are

442 different in the analyzed species. This conclusion is in accordance with earlier studies that suggest

443 conserved covariation patterns in primates and other mammals in cranial parts other than the jaws

444 (Cheverud, 1996b; Ackermann and Cheverud, 2000; Lieberman et al., 2000; Marroig and Cheverud,

445 2001; Ackermann, 2002; Gonzalez-Jose et al., 2004; Marroig et al., 2004; Ackermann, 2005; Goswami,

446 2006; Gunz and Harvati, 2007; Mitteroecker and Bookstein, 2008; Porto et al., 2009; Makedonska et al.,

447 2012; Villmoare et al., 2014).

To evaluate the magnitude of the covariation we used the covariance ratio (CR, Adams, 2016)

449 and the correlations between upper and lower arcades, or the premaxilla and the maxilla, respectively.

450 For the CR we considered the distributions from permutations. Homo stands out in showing lower

451 overall CR values (Fig.5, Table 4). Covariation magnitudes of individual PLS axes are quantified by the

452 correlation coefficient. When the first PLS is considered, which explains almost two thirds of the total 
453 covariance (i.e., arcade shapes from U-shaped to parabolic), Gorilla shows the weakest covariation,

454 followed by Homo, Pongo, and Pan which show similar covariation magnitudes. Hylobates has slightly

455 higher values (Table 5). Thus the magnitude of covariation does not reflect the shape gradient from U-

456 shaped to parabolic, and might be more taxon specific than arcade shape specific. In PLS2, which

457 explains almost $22 \%$ of the total covariance (i.e., canine size), Homo and Hylobates display lower

458 correlations than the other groups. Interestingly, while it seems as if absolute canine size itself is of

459 minor importance for the magnitude of covariation, this result might indicate that sexual dimorphism in

460 canine size contributes to the magnitude of covariation, in a way that less dimorphic taxa show lower

461 magnitudes of covariation. In PLS3, that explains about $8 \%$ of the total covariance (i.e., spatial

462 arrangement of anterior dentition and postcanine divergence), Homo and Hylobates also show lower

463 values, followed by Gorilla which falls in-between the latter and Pan and Pongo (Fig. 5d). These

464 differences in covariation magnitudes might be related to different strategies of incorporating large

465 canines into the dental arcade. While in Pan, Pongo and Gorilla intercanine distance is enlarged, which

466 results in a flat anterior region, in Hylobates the incisal region is extended anteriorly, resulting in a V-

467 shaped arcade. The lower magnitudes in Homo might be the consequence of the generally reduced

468 canines. In combination with the results for the overall measure for the magnitude of covariation these

469 findings imply that the lower magnitude in modern humans is not a reflection of the large-scale

470 differences between humans and apes.

471 While hominoids do show variation in dental morphology and dental size proportions, the

472 pattern of the interplay between upper and lower arcades remained generally unchanged. This suggests

473 that selection acted on maintaining a proper fit between the upper and the lower arcade. The lower

474 magnitudes of maxillo-mandibular covariation in modern humans which we report here may be related

475 to a systemic change in the hominin lineage. It was shown previously that magnitudes of covariation in

476 the cranium and the pelvis are relaxed in modern humans in general compared to other primates and 
mammals (Marroig et al., 2009; Porto et al., 2009; Grabowski et al., 2011). Following this argument, a

478 relaxation initially allowed new body plans characteristic of hominins to emerge, potentially including

479 the development of the parabolic arcade shape. If lower magnitudes can account for the development

480 of hominin morphologies then they should be identifiable before new morphologies appear, i.e., at or

481 shortly after the split from the chimpanzee lineage. While the resolution of the current fossil record

482 might not be good enough to determine when this relaxation occurred in the hominin lineage, fossil

483 evidence from about 2.1 to 1.5 million years ago suggests that bipedal adaptations, brain enlargement

484 and short and rounded dental arcades are not necessarily associated with each other. While brain size of

485 H. habilis, H. rudolfensis and H. erectus largely overlap in range, they show distinct facial morphologies

486 including the primitive morphology of long and parallel post-canine tooth rows in $H$. habilis, the derived

487 condition in $H$. erectus, and the distinct morphology of $H$. rudolfensis with short and parallel post-canine

488 tooth rows plus a flat anterior region (Spoor et al., 2015). While these seemingly conflicting lines of

489 evidence clearly need more data, another, mutually non-exclusive, explanation for a lower covariation in

490 Homo compared to all apes could be diet. It has been found that those platyrrhine species consuming

491 softer foods show lower magnitudes of covariation than species reliant on harder foods (Marroig and

492 Cheverud, 2001; Makedonska et al., 2012). A similar relationship could contribute to the difference we

493 found between apes and modern humans. This would be in accordance with the notion that at least in

$494 H$. sapiens the masticatory effort was reduced due to extra-oral food processing via tool use and cooking

495 (e.g. Brace et al., 1987; Wrangham et al., 1999; Richards et al., 2001; Teaford et al., 2002; Henry, 2010).

496 This explanation, however, does not sufficiently explain the differences we observe between ape

497 genera, which show similar magnitudes of covariation but at the same time different dietary habits.

498 We also analyzed the pattern and magnitudes of covariation between the premaxilla and the

499 maxilla. Corroborating the results of Villmoare et al. (2014) the magnitudes of covariation between the

500 premaxilla and the maxilla are in general slightly lower than between the upper and the lower jaw. 
In the first PLS components, all groups follow a similar pattern of covariation between the

502 premaxilla and the maxilla. When canines are large, incisors are placed anteriorly to create a diastema

503 for the lower canine. The posterior dentition is long and parallel. With the reduction of canine and

504 diastema size, incisors move posteriorly and the posterior arcades get more parabolic (PLS1). This

505 finding of a shared pattern of covariation between the premaxilla and the maxilla as well as Homo falling

506 within the apes' range of covariation magnitude is in accordance with Villmoare et al. (2014). Either

507 result shows that the variation in hominin premaxilla is not associated with a change in the pattern of

508 character covariation. Previous studies suggested that there is a relation between anterior tooth size

509 and premaxilla size (Bromage, 1989; Mooney and Siegel, 1991; Lockwood, 1997; Braga, 1998). Our

510 results show that canine and diastema size contributes substantially to maxillary arcade shape.

511 To assess differences related to sexual dimorphism, we evaluated magnitudes of covariation for

512 females and males in each group between the upper and the lower jaw (SOM Fig. S6) and between the

513 premaxilla and the maxilla (SOM Fig. S9). Magnitudes of the latter overlap almost completely in all

514 groups except for Pan and Gorilla, where males show higher values. Mean magnitudes between the

515 upper and the lower jaw are higher in females except for Hylobates, where males have higher values.

516 Due to small sample sizes in the within-group comparisons these results should be treated with caution.

517 Additionally, an uncertainty about modern human sex attribution must be considered, since their sexing

518 is based on traditional morphological methods, rather than actual records (dissection, autopsy or

519 graveyard). In general, it is probable that the mechanisms responsible for the results presented here

520 might be multiple and different for each taxon as there are different patterns and magnitudes of

521 dimorphism between species (Plavcan, 2002).

Our results suggest that variation in hominoid arcade shape is not the consequence of a change

523 of the underlying covariation patterns. Our results provide a model for the evolutionary arcade shape 
524 change in the hominin lineage: with the loss of interlocking canines and the decreased need for space in

525 the antagonistic arcade in the hominin lineage, the tooth rows become more rounded and eventually

526 parabolic. Driven by the necessity of the upper and the lower jaw to form an effective masticatory

527 apparatus, the morphological covariation between the mandibular and the maxillary arcade has been

528 maintained.

The strong focus on dentognathic structures in palaeoanthropology is due to their good

530 preservation and their taxonomic significance. Nonetheless, our limited understanding of the degree

531 and pattern of intraspecific variation has resulted in different views regarding the number of species

532 that can be recognized in the fossil record (e.g. Wood, 1992; Rightmire, 1993; Leakey et al., 2012).

533 Another factor adding to differences in hypodigm composition is that there is a lack of consensus over

534 which maxillae and mandibles can be accommodated within a single species (Spoor et al., 2015). The

535 results of the current study will help address these issues, as they provide reference data which

536 document the intraspecific and interspecific variation of the upper and lower dental arcades in extant

537 taxa. Moreover, the degree and pattern of covariation between upper and lower jaws can help with

538 identifying the probability that certain maxillae and mandibles in the fossil record are conspecific. Using

539 a smaller landmark set, we have shown recently that this approach can indeed be used to recognize

540 distinct morphs within early Homo, identifying those pairs of maxillae and mandibles which, based on

541 extant hominid variation, can be excluded statistically from belonging to a single species (Spoor et al.,

542 2015).

543

\section{Conclusion}

We found that Pan, Gorilla, Pongo, Hylobates, and Homo share a very similar covariation pattern

546 between the upper and the lower arcade, as well as between the premaxilla and the maxilla, that is 
547 independent from dental spatial arrangements. We suggest that in the hominin lineage, with the

548 reduction of canine and diastema size, the incisors move posteriorly and the whole arcade becomes

549 parabolic. The upper and the lower arcades keep track of each other through high magnitudes of

550 covariation. Modern humans show lower magnitudes of covariation between the upper and the lower

551 jaw compared to apes, which might be related to a mechanically less challenging diet in living humans.

552 Alternatively or additionally, lower magnitudes might follow from a general relaxation in covariation

553 attributable to a systemic change in the hominin lineage that enabled the development of new shapes in

554 the first place.

555

556 Acknowledgements

We are grateful to Alexander Stoessel for his constructive feedback on this manuscript and the

558 anonymous reviewers and the editors for the helpful comments. We thank the following curators and

559 museums for access to their specimens: Ingo Bechmann and Christine Feja, Anatomisches Institut der

560 Universität Leipzig; Ottmar Kullmer and Friedemann Schrenk, Senckenberg Museum, Frankfurt/Main;

561 Frieder Mayer and Nora Lange, Museum für Naturkunde, Berlin; the Ivorian authorities and Christophe

562 Boesch, MPI-EVA, Leipzig; the Natural History Museum, London; S. Ivan Perez, Facultad de Ciencias

563 Naturales y Museo, Universidad Nacional de la Plata, Buenos Aires; the Smithsonian's Division of

564 Mammals (Dr. Kristofer Helgen); Martin Fischer, Phyletisches Museum Jena; Lynn Copes for providing

565 the modern human scans and the Human Origins Program (Dr. Matt Tocheri), Washington, D.C., for the

566 scans of USNM specimens used in this research (http://humanorigins.si.edu/evidence/3d-

567 collection/primate). These scans were acquired through the generous support of the Smithsonian 2.0

568 Fund and the Smithsonian's Collections Care and Preservation Fund. We thank Jean-Jacques Hublin for

569 supporting this research, which was funded by the Max Planck Society. 


\section{References}

572 Ackermann, R.R., 2002. Patterns of covariation in the hominoid craniofacial skeleton: implications for 573 paleoanthropological models. J. Hum. Evol. 43, 167-187.

574 Ackermann, R.R., 2005. Ontogenetic integration of the hominoid face. J. Hum. Evol. 48, 175-197.

575 Ackermann, R.R., Cheverud, J.M., 2000. Phenotypic covariance structure in tamarins (genus Saguinus): A 576 comparison of variation patterns using matrix correlation and common principal component 577 analysis. Am. J. Phys. Anthropol. 111, 489-501.

578 Adams, D.C., 2016. Evaluating modularity in morphometric data: challenges with the RV coefficient and a new test measure. Methods Ecol. Evol. 7, 565-572.

Almquist, A.J., 1974. Sexual differences in the anterior dentition in African primates. Am. J. Phys. Anthropol. 40, 359-367.

Anapol, F., Lee, S., 1994. Morphological adaptation to diet in platyrrhine primates. Am. J. Phys. Anthropol. 94, 239-261.

Angle, E.H., 1899. Classification of malocclusion. The Dental Cosmos 41, 248-264.

Armelagos, G.J., Van Gerven, D.P., Goodman, A.H., Calcagno, J.M., 1989. Post-Pleistocene facial reduction, biomechanics and selection against morphologically complex teeth: a rejoinder to Macchiarelli and Bondioli. Hum. Evol. 4, 1-7.

Black, G.V., 1902. Descriptive Anatomy of the Human Teeth, 5th edition. SS White Manufacturing Company, Philadelphia.

Boesch, C., Bi, G., Bertin, Z., Anderson, D.P., Stahl, D., 2006. Food choice in Tai chimpanzees: are cultural

593 Bookstein, F., 2016. The inappropriate symmetries of multivariate statistical analysis in geometric 594 morphometrics. Evol. Biol. 43, 277-313.

595 Bookstein, F.L., 1991. Morphometric Tools for Landmark Data: Geometry and Biology. Cambridge $596 \quad$ University Press, Cambridge. 
Bookstein, F.L., Gunz, P., Mitteroecker, P., Prossinger, H., Schaefer, K., Seidler, H., 2003. Cranial integration in Homo: singular warps analysis of the midsagittal plane in ontogeny and evolution. J. Hum. Evol. 44, 167-187.

Bouvier, M., 1986. A biomechanical analysis of mandibular scaling in Old World monkeys. Am. J. Phys. Anthropol. 69, 473-482.

Brace, C.L., Rosenberg, K.R., Hunt, K.D., 1987. Gradual change in human tooth size in the Late Pleistocene and Postpleistocene. Evolution 41, 705-720.

Brader, A.C., 1972. Dental arch form related with intraoral forces: PR= C. Am. J. Orthod. 61, 541-561.

Braga, J., 1998. Chimpanzee variation facilitates the interpretation of the incisive suture closure in South African Plio-Pleistocene hominids. Am. J. Phys. Anthropol. 105, 121-135.

Bromage, T.G., 1989. Ontogeny of the early hominid face. J. Hum. Evol. 18, 751-773.

Broomell, I.N., 1902. Anatomy and Histology of the Mouth and Teeth. P. Blackiston's Son \& Co, Philadelphia.

Carlson, D.S., Vangerven, D.P., 1977. Masticatory function and post-Pleistocene evolution in Nubia. Am. J. Phys. Anthropol. 46, 495-506.

Cassidy, K.M., Harris, E.F., Tolley, E.A., Keim, R.G., 1998. Genetic influence on dental arch form in orthodontic patients. Angle Orthod. 68, 445-454.

Cheverud, J.M., 1996a. Developmental integration and the evolution of pleiotropy. Am. Zool. 36, 44-50.

Cheverud, J.M., 1996b. Quantitative genetic analysis of cranial morphology in the cotton-top (Saguinus oedipus) and saddle-back (S. fuscicollis) tamarins. J. Evol. Biol. 9, 5-42.

Clarke, R.J., 2012. A Homo habilis maxilla and other newly-discovered hominid fossils from Olduvai Gorge, Tanzania. J. Hum. Evol. 63, 418-428.

Copes, L., 2012. Comparative and experimental investigations of cranial robusticity in mid-Pleistocene hominins. Doctoral dissertation. Arizona State University.

Corruccini, R.S., 1991. Anthropological aspects of orofacial and occlusal variations and anomalies. In: Kelley, M.A., Larsen, C.S. (Eds.), Advances in Dental Anthropology. Wiley-Liss, New York, pp. 295323. 
624 Courtenay, J., Groves, C.P., Andrews, P., 1998. Interor intra-island variation? An assessment of the 625 differences between Bornean and Sumatran orangutans. In: Schwartz, J.H. (Ed.), Orang-utan Biology. Oxford University Press, New York, pp. 19-29.

627 Currier, J.H., 1969. A computerized geometric analysis of human dental arch form. Am. J. Orthod. 56, 164-179.

Doran-Sheehy, D., Mongo, P., Lodwick, J., Conklin-Brittain, N.L., 2009. Male and female western gorilla fiet: preferred foods, use of fallback resources, and implications for ape versus Old World monkey foraging strategies. Am. J. Phys. Anthropol. 140, 727-738.

Engel, G.A., 1979. Preformed arch wires: reliability of fit. Am. J. Orthod. 76, 497-504.

Fruciano, C., Franchini, P., Meyer, A., 2013. Resampling-based approaches to study variation in morphological modularity. PLOS ONE 8, e69376.

Galdikas, B.M.F., 1988. Orangutan Diet, Range, and Activity at Tanjung Puting, Central Borneo. Int. J. Primatol. 9, 1-35.

Garn, D.H., 1968. Human dental arch form determination from cranial anatomy through conic section geometry. M. S. Thesis. Temple University School of Dentistry, Philadelphia.

Genet-Varcin, E., 1969. A la Recherche du Primate Ancêtre de l'Homme: Primates et Évolution. Editions Boubée, Paris.

Gittins, S.P., Raemaekers, J.J., 1980. Siamang, lar and agile gibbons. In: Chivers, D.J. (Ed.), Malayan Forest Primates: Ten Years Study in Tropical Rainforest. Plenum, New York, pp. 63-195.

Gonzalez-Jose, R., Van der Molen, S., Gonzalez-Perez, E., Hernandez, M., 2004. Patterns of phenotypic

Good, P., 2000. Permutation Tests: A Practical Guide To Resampling Methods For Testing Hypotheses. covariation and correlation in modern humans as viewed from morphological integration. Am. J.

648 Goswami, A., 2006. Morphological integration in the carnivoran skull. Evolution 60, 169-183.

649 Grabowski, M.W., Polk, J.D., Roseman, C.C., 2011. Divergent patterns of integration and reduced constraint in the human hip and the origins of bipedalism. Evolution 65, 1336-1356. 
651 Greenfield, L.O., 1992. Origin of the human canine: a new solution to an old enigma. Yearb. Phys.

$652 \quad$ Anthropol. 35, 153-185.

653 Groves, C.P., 1970. Population Systematics of Gorilla. J. Zool. 161, 287-300.

654 Groves, C.P., 1972. Systematics and phylogeny of gibbons. In: Rumbaugh, D.M. (Ed.), Gibbon and 655 Siamang. Karger, Basel, pp. 1-89.

656 Groves, C.P., Westwood, C., Shea, B.T., 1992. Unfinished business, Mahalanobis and a clockwork orang. 657 J. Hum. Evol. 22, 327-340.

658 Gunz, P., Harvati, K., 2007. The Neanderthal "chignon": variation, integration, and homology. J. Hum. Evol. 52, 262-274.

Guy, F., Brunet, M., Schmittbuhl, M., Viriot, L., 2003. New approaches in hominoid taxonomy: Morphometrics. Am. J. Phys. Anthropol. 121, 198-218.

Hellman, M., 1919. Dimensions vs. form in teeth and their bearing on the morphology of the dental arch. Int. J. Orthod. Oral Surg. 5, 615-651.

Hellman, M., 1942. Factors influencing occlusion. Angle Orthod. 12, 3-27.

Henry, A.G., 2010. Plant foods and the dietary ecology of Neandertals and modern humans. Doctoral dissertation. George Washington University.

667 Herring, S.W., 1993. Functional morphology of mammalian mastication. Am. Zool. 33, 289-299.

668 Hrdlicka, A., 1940. Lower jaw. Am. J. Phys. Anthropol. 27, 281-308.

669 Hylander, W., 1972. Functional significance of Eskimo craniofacial morphology. Am. J. Phys. Anthropol. $670 \quad 37,441$.

671 Hylander, W.L., 1975. Incisor Size and Diet in Anthropoids with Special Reference to Cercopithecidae. $672 \quad$ Science 189, 1095-1098.

673 Hylander, W.L., 1979. Functional significance of primate mandibular form. J. Morphol. 160, 223-239.

674 Johanson, D.C., White, T.D., 1979. A systematic assessment of early African hominids. Science 203, 321675330.

676 Johanson, D.C., White, T.D., Coppens, Y., 1978. A new species of the genus Australopithecus (Primates: 677 Hominidae) from the Pliocene of eastern Africa. Kirtlandia 28, 1-14. 
678 Kay, R.F., Hylander, W.L., 1978. The dental structure of mammalian folivores with special reference to 679 primates and Phalangeroidea (Marsupialia). In: Montgomery, G.C. (Ed.), The Ecology of Arboreal Folivores. Smithsonian Institution Press, Washington, pp. 173-191.

Kelley, J., 1995. Sexual dimorphism in canine shape among extant great apes. Am. J. Phys. Anthropol. 96, 365-389.

Kimbel, W.H., Delezene, L.K., 2009. "Lucy" redux: A review of research on Australopithecus afarensis. Yearb. Phys. Anthropol. 52, 2-48.

Kimbel, W.H., Johanson, D.C., Rak, Y., 1997. Systematic assessment of a maxilla of Homo from Hadar, Ethiopia. Am. J. Phys. Anthropol. 103, 235-262.

Klingenberg, C.P., McIntyre, G.S., 1998. Geometric morphometrics of developmental instability: Analyzing patterns of fluctuating asymmetry with Procrustes methods. Evolution 52, 1363-1375.

Knott, C.D., 1998. Changes in orangutan caloric intake, energy balance, and ketones in response to fluctuating fruit availability. Int. J. Primatol. 19, 1061-1079.

Larsen, C.S., 1995. Biological changes in human populations with agriculture. A. Rev. Anthropol. 24, 185213.

Le Gros Clark, W.E., 1950. Hominid characters of the australopithecine dentition. J. Roy. Anthropol. Inst. $80,37-54$.

Leakey, M.G., Spoor, F., Dean, M.C., Feibel, C.S., Anton, S.C., Kiarie, C., Leakey, L.N., 2012. New fossils from Koobi Fora in northern Kenya confirm taxonomic diversity in early Homo. Nature 488, $201-$

Leutenegger, W., Kelly, J.T., 1977. Relationship of sexual dimorphism in canine size and body size to 204.

Leutenegger, W., Shell, B., 1987. Variability and sexual dimorphism in canine size of Australopithecus and extant hominoids. J. Hum. Evol. 16, 359-367. Anthropol. 17, 55-68.

704 Lieberman, D.E., Ross, C.F., Ravosa, M.J., 2000. The primate cranial base: ontogeny, function, and 705 integration. Am. J. Phys. Anthropol. 113.S31, 117-169. 
Lockwood, C.A., 1997. Variation in the face of Australopithecus africanus and other African hominoids. Doctoral dissertation. University of the Witwatersrand.

MacConaill, M.A., Scher, E.A., 1949. The ideal form of the human dental arcade, with some prosthetic application. Dent. Rec. 69, 285-302.

MacKinnon, J., 1974. Behavior and Ecology of Wild Orangutans (Pongo pygmaeus). Anim. Behav. 22, 374.

Makedonska, J., Wright, B.W., Strait, D.S., 2012. The effect of dietary adaption on cranial morphological integration in capuchins (Order Primates, Genus Cebus). PLOS ONE 7, e40398.

Mardia, K.V., Bookstein, F.L., Moreton, I.J., 2000. Statistical assessment of bilateral symmetry of shapes. Biometrika 87, 285-300.

Marroig, G., Cheverud, J.M., 2001. A comparison of phenotypic variation and covariation patterns and the role of phylogeny. Ecology, and ontogeny during cranial evolution of New World monkeys. Evolution 55, 2576-2600.

Marroig, G., Shirai, L.T., Porto, A., de Oliveira, F.B., De Conto, V., 2009. The Evolution of Modularity in the Mammalian Skull II: Evolutionary Consequences. Evol. Biol. 36, 136-148.

Marroig, G., Vivo, M., Cheverud, J.M., 2004. Cranial evolution in sakis (Pithecia, Platyrrhini) II: evolutionary processes and morphological integration. Evol. Biol. 17, 144-155.

McCollum, M.A., Ward, S.C., 1997. Subnasoalveolar anatomy and hominoid phylogeny: evidence from comparative ontogeny. Am. J. Phys. Anthropol. 102, 377-405.

McConkey, K.R., Ario, A., Aldy, F., Chivers, D.J., 2003. Influence of forest seasonality on gibbon food choice in the rain forests of Barito Ulu, Central Kalimantan. Int. J. Primatol. 24, 19-32.

Mitteroecker, P., Bookstein, F., 2007. The conceptual and statistical relationship between modularity and morphological integration. Syst. Biol. 56, 818-836.

Mitteroecker, P., Bookstein, F., 2008. The evolutionary role of modularity and integration in the hominoid cranium. Evolution 62, 943-958.

Mitteroecker, P., Gunz, P., 2009. Advances in Geometric Morphometrics. Evol. Biol. 36, 235-247. 
732

733

734

735

736

737

738

739

740

741

742

743

744

745

746

747

748

749

750

751

752

753

754

755

756

757

758

759

Mitteroecker, P., Gunz, P., Windhager, S., Schaefer, K., 2013. A brief review of shape, form, and allometry in geometric morphometrics, with applications to human facial morphology. Hystrix 24, 59-66.

Mooney, M.P., Siegel, M.I., 1991. Premaxillary-maxillary suture fusion and anterior nasal tubercle morphology in the chimpanzee. Am. J. Phys. Anthropol. 85, 451-456.

Noback, M.L., Harvati, K., 2015. Covariation in the human masticatory apparatus. Anat. Rec. 298, 64-84.

Oxnard, C.E., Lieberman, S.S., Gelvin, B.R., 1985. Sexual dimorphisms in dental dimensions of higher primates. Am. J. Primatol. 8, 127-152.

Plavcan, J.M., 1993. Canine size and shape in male anthropoid primates. Am. J. Phys. Anthropol. 92, 201216.

Plavcan, J.M., 2002. Taxonomic variation in the patterns of craniofacial dimorphism in primates. J. Hum. Evol. 42, 579-608.

Plavcan, J.M., van Schaik, C.P., 1992. Intrasexual competition and canine dimorphism in anthropoid primates. Am. J. Phys. Anthropol. 87, 461-477.

Porto, A., de Oliveira, F.B., Shirai, L.T., De Conto, V., Marroig, G., 2009. The evolution of modularity in the mammalian skull I: morphological integration patterns and magnitudes. Evol. Biol. 36, 118135.

Prasad, M., Hussain, M.Z., Shetty, S.K., Kumar, T.A., Khaur, M., George, S.A., Dalwai, S., 2013. Median mandibular flexure at different mouth opening and its relation to different facial types: $A$ prospective clinical study. J. Nat. Sci. Biol. Med. 4, 426-430.

Preuschoft, H., 1989. Biomechanical approach to the evolution of the facial skeleton of hominoid primates. Fortschr. Zool. 35, 421-431.

Preuschoft, H., Witzel, U., 2004. Functional structure of the skull in hominoidea. Folia Primatol. 75, 219252.

Ravosa, M.J., 1990. Functional assessment of subfamily variation in maxillomandibular morphology among Old World monkeys. Am. J. Phys. Anthropol. 82, 199-212.

Remane, A., 1921. Beiträge zur Morphologie des Anthropoidengebisses. Archiv für Naturgeschichte. Abteilung A 87, 1-179. 
Richards, M.P., Pettitt, P.B., Stiner, M.C., Trinkaus, E., 2001. Stable isotope evidence for increasing dietary breadth in she European mid-Upper Paleolithic. Proc. Natl. Acad. Sci. 98, 6528-6532.

Rightmire, G.P., 1993. Variation among early Homo crania from Olduvai Gorge and the Koobi Fora region. Am. J. Phys. Anthropol. 90, 1-33.

Rijksen, H.D., 1978. A fieldstudy on Sumatran orang utans (Pongo pygmaeus abelii, Lesson 1827): Ecology, behaviour and conservation. Doctoral dissertation. Mededelingen Landbouwhogeschool Wageningen, Netherlands.

Rogers, M.E., Abernethy, K., Bermejo, M., Cipolletta, C., Doran, D., McFarland, K., Nishihara, T., Remis, M., Tutin, C.E.G., 2004. Western gorilla diet: A synthesis from six sites. Am. J. Primatol. 64, 173192.

Rohlf, F.J., Corti, M., 2000. Use of two-block partial least-squares to study covariation in shape. Syst. Biol. 49, 740-753.

Rohlf, F.J., Slice, D., 1990. Extensions of the Procrustes method for the optimal superimposition of landmarks. Syst. Zool. 39, 40-59.

Rörer-Ertl, O., 1984. Orang-Utan-Studien. Hironymus Verlag, Neuried.

Sardi, M.L., Ramirez Rozzi, F., Pucciarelli, H.M., 2004. The Neolithic transition in Europe and North Africa. The functional craneology contribution. Anthropol. Anz. 62, 129-145.

Schmittbuhl, M., Rieger, J., Le Minor, J.M., Schaaf, A., Guy, F., 2007. Variations of the mandibular shape in extant hominoids: Generic, specific, and subspecific quantification using elliptical Fourier analysis in lateral view. Am. J. Phys. Anthropol. 132, 119-131.

Schwartz, J.H., 1995. Skeleton Keys: An Introduction To Human Skeletal Morphology, Development, and Analysis. Oxford University Press, New York.

Scott, J.H., 1957. The shape of the dental arches. J. Dent. Res. 36, 996-1003.

Smilde, A.K., Kiers, H.A.L., Bijlsma, S., Rubingh, C.M., van Erk, M.J., 2009. Matrix correlations for highdimensional data: the modified RV-coefficient. Bioinformatics 25, 401-405.

Spoor, F., Gunz, P., Neubauer, S., Stelzer, S., Scott, N., Kwekason, M., Dean, C., 2015. Reconstructed Homo habilis holotype $\mathrm{OH} 7$ suggests deep-rooted species diversity in early Homo. Nature 513, 83-86. 
Teaford, M.F., Ungar, P.S., Grine, F.E., 2002. Paleontological evidence for the diets of African PlioPleistocene hominins with special reference to early Homo. In: Ungar, P.S., Teaford, M.F. (Eds.), Human Diet: Its Origin and Evolution. Bergin \& Garvey, Westport, CT, pp. 143-166.

Tobias, P.V., 1967. Olduvai Gorge. Vol. 2. The Cranium and Maxillary Dentition of Australopithecus (Zinjanthropus) boisei. Camebridge University Press, Camebridge.

Tobias, P.V., 1991. Olduvai Gorge IV: The Skulls, Endocasts and Teeth of Homo habilis. Cambridge University Press, Cambridge.

Tutin, C.E.G., Fernandez, M., 1993. Composition of the Diet of Chimpanzees and Comparisons with That of Sympatric Lowland Gorillas in the Lope Reserve, Gabon. Am. J. Primatol. 30, 195-211.

Uchida, A., 1998. Variation in tooth morphology of Gorilla gorilla. J. Hum. Evol. 34, 55-70.

Villmoare, B.A., Dunmore, C., Kilpatrick, S., Oertelt, N., Depew, M.J., Fish, J.L., 2014. Craniofacial modularity, character analysis, and the evolution of the premaxilla in early African hominins. J. Hum. Evol. 77, 143-154.

von Cramon-Taubadel, N., 2011. Global human mandibular variation reflects differences in agricultural and hunter-gatherer subsistence strategies. Proc. Natl. Acad. Sci. 108, 19546-19551.

Ward, C.V., Leakey, M.G., Walker, A., 2001. Morphology of Australopithecus anamensis from Kanapoi and Allia Bay, Kenya. J. Hum. Evol. 41, 255-368.

Watts, D.P., 1984. Composition and Variability of Mountain Gorilla Diets in the Central Virungas. Am. J. Primatol. 7, 323-356.

Weidenreich, F., 1936. The mandibles of Sinanthropus pekinensis: a comparative study. Palaeontologia Sinica, Series D 3, 162.

Weijs, W.A., Hillen, B., 1984. Relationships between masticatory muscle cross-section and skull shape. J. Dent. Res. 63, 1154-1157.

Weijs, W.A., Hillen, B., 1986. Correlations between the cross-sectional area of the jaw muscles and craniofacial size and shape. Am. J. Phys. Anthropol. 70, 423-431.

White, T.D., Suwa, G., Simpson, S., Asfaw, B., 2000. Jaws and teeth of Australopithecus afarensis from Maka, Middle Awash, Ethiopia. Am. J. Phys. Anthropol. 111, 45-68. 
815 Witzel, U., Preuschoft, H., 1999. The bony roof of the nose in humans and other primates. Zool. Anz. $816 \quad 238,103-115$.

817 Witzel, U., Preuschoft, H., 2002. Function-dependent shape characteristics of the human skull. $818 \quad$ Anthropol. Anz. 60, 113-135.

819 Wold, H., 1966. Estimation of principal components and related models by iterative least squares. In:

820 Krishnaiaah, P.R. (Ed.), Multivariate Analysis. Academic Press, New York, pp. 391-420.

821 Wolfram Research Inc., 2010. Mathematica. Wolfram Research Inc., Champaign, Illinois.

822 Wood, B., 1991. Hominid Cranial Remains From Koobi Fora. Clarendon Press, Oxford.

823 Wood, B., 1992. Origin and evolution of the genus Homo. Nature 355, 783-790.

824 Wrangham, R.W., Jones, J.H., Laden, G., Pilbeam, D., Conklin-Brittain, N., 1999. The raw and the stolen: 825 Cooking and the ecology of human origins. Curr. Anthrop. 40, 567-594.

826 Young, N.M., Wagner, G.P., Hallgrimsson, B., 2010. Development and the evolvability of human limbs.

827 Proc. Natl. Acad. Sci. 107, 3400-3405.

828 


\section{Figure captions}

Figure 1. Data acquisition. Landmarks are placed on the alveolar margin (blue) and on the cervix

831 of the postcanine dentition (orange) of the maxilla (a) and the mandible (c); b) and d) show the

832 wireframe of the symmetrized data.

Figure 2. Arcade shape space of maxillae $(a, b)$ and mandibles (c). Homo is shown in yellow, Pan

834 in blue, Gorilla in black, Pongo in red, and Hylobates in green. The wireframes show the shape variation

835 along PC1, PC2 and PC3. In PC3, Hylobates mandibles plot similarly to the maxillae and are therefore not 836 shown.

Figure 3. Two-block partial least squares (PLS) analysis between the maxillary and the

838 mandibular arcade. Group colors as in Figure 2. The wireframes show the shape changes along SW1 (a),

839 SW2 (b), and SW3 (c). All groups scatter along the diagonal. Hylobates shows a shift along SW2, parallel

840 with the hominid trajectory.

Figure 4. Two-block partial least squares (PLS) analysis between the maxillary and the

842 mandibular arcade for each group separately: Pan (a), Gorilla (b), Pongo (c), Homo (d), and Hylobates

843 (e). Males are shown in dark, females in light colors. The wireframes show the shape changes along

844 SW1.

Figure 5. Distribution of the covariance ratio (CR) (sample size 30, 1000 iterations). Homo shows

846 lower overall values than the apes

Figure 6. Female (red) and male (blue) mean shapes for the maxilla (a-e) and the mandible (f-j).

848 Mean shape differences statistically significant at $\alpha \leq 0.05 ; p$-values given below the wireframe. Female

849 and male arcades are significantly different between Pan, Gorilla, Pongo, and Homo (maxillae). Homo

850 mandibles and Hylobates are not significantly different. Smaller canines (females) are associated with a 
851 more posteriorly placed anterior arcade. In the postcanine row, the premolars are placed more

852 anteriorly, the molars remain unaffected.

853 Figure 7. PLS analysis between the premaxilla (anterior, black wireframe) and the maxilla

854 (posterior, red wireframe). Group colors as in Figure 2.

Figure 8. Distributions of the CR (sample size 30, 1000 iterations) between the premaxilla and

856 the maxilla.

SOM Figure S1. Species distribution within the genus Gorilla in arcade shape space of maxillae

$858(a, b)$ and mandibles (c). G. gorilla is shown in black, G. beringei in gray. The wireframes show the shape

859 variation along PC1, PC2 and PC3.

860

SOM Figure S2. Species distribution within the genus Pongo in arcade shape space of maxillae (a,

861 b) and mandibles (c). P. pygmaeus is shown in light red, P. abelii in yellow, Pongo sp. in dark red. The

862 wireframes show the shape variation along PC1, PC2 and PC3.

863 SOM Figure S3. Species distribution within the genus Hylobates in arcade shape space of

864 maxillae (a, b) and mandibles (c). H. muelleri is shown in green, $H$. lar in pink, $H$. klossii in orange, $H$.

865 albibarbis in blue, H. agilis in yellow. The wireframes show the shape variation along PC1, PC2 and PC3.

866 SOM Figure S4. Shape changes along SW1, SW2, SW3 between the maxillary arcade (black) and

867 mandibular arcade (red) for each group separately. The left wireframe in each group is the negative

868 extreme, the right wireframe is the positive extreme for each SW.

869 SOM Figure S5. PLS scores of the maxillary and the mandibular arcade for each group

870 separately. Dark colors in each group are males, light colors females.

871 SOM Figure S6. Sexual dimorphism in the magnitude of covariation. For each taxon, distributions

872 (sample size 15, 1000 iterations) and single values (horizontal lines) are given. Light group colors are 
873 females, dark group colors are males. Female hominids show higher magnitudes (distributions and

874 single values) than their male counterparts. Hylobates show the opposite pattern. In Pan, the single

875 values are almost the same.

876 SOM Figure S7. PLS scores of the premaxilla and the maxilla for each group separately. Dark

877 colors in each group are males, light colors females.

878 SOM Figure S8. Shape changes along SW1 (a), SW2 (b), and SW3 (c) between the premaxilla

879 (black) and the maxilla (red). The left column is the negative extreme, the right column is the positive

880 extreme.

881 SOM Figure S9. Sexual dimorphism in the covariance ratio (CR) between the premaxilla and the

882 maxilla. For each taxon distributions subsample size is 15 (1000 iterations); light group colors are

883 females, dark group colors are males. 
Table 1

Table 1. Sample composition

\begin{tabular}{lccc}
\hline Taxon & + & $\hat{0}$ & Unknown sex \\
\hline Pan & 25 & 19 & - \\
Homo & 16 & 24 & 13 \\
Gorilla & 22 & 31 & - \\
Pongo & 25 & 27 & - \\
Hylobates & 29 & 30 & 4 \\
\hline
\end{tabular}


Table 2. Results of the PC analyses.

\begin{tabular}{lcrr}
\hline & Eigenvalues & \% variance & Cumulative \% \\
\hline Maxillae & & & \\
PC1 & 0.00789125 & 66.958 & 66.958 \\
PC2 & 0.00129874 & 11.02 & 77.978 \\
PC3 & 0.00067848 & 5.757 & 83.735 \\
Mandibles & & & \\
PC1 & 0.01059464 & 70.795 & 70.795 \\
PC2 & 0.00163547 & 10.928 & 81.723 \\
PC3 & 0.00093735 & 6.264 & 87.987 \\
\hline
\end{tabular}


Table 3. Percentage of the explained covariance between the upper and the lower arcade for the first five PLS components. Symmetrized data; combined PLS: group-mean centered; separate PLS: sex-mean centered.

\begin{tabular}{lc|rrrrr}
\hline & $\begin{array}{c}\text { \% covariance } \\
\text { combined PLS }\end{array}$ & \multicolumn{5}{|c}{ \% covariance separate PLS } \\
\hline & & Pan & Gorilla & Pongo & Homo & Hylobates \\
\hline PLS1 & 61.39 & 68.44 & 51.79 & 57.80 & 65.53 & 79.40 \\
PLS 2 & 21.55 & 11.74 & 19.31 & 15.00 & 13.27 & 8.78 \\
PLS 3 & 7.92 & 6.26 & 13.06 & 10.85 & 6.55 & 4.44 \\
PLS 4 & 3.46 & 3.50 & 3.83 & 6.38 & 3.41 & 1.36 \\
PLS 5 & 1.38 & 2.60 & 2.65 & 2.39 & 2.09 & 1.27 \\
\hline
\end{tabular}


Table 4. Results for the $C R$ and the permutation tests for the upper and the lower jaw. Subsample size for the permutation is 30,1000 resamples. Below, Bonferroni corrected $p$-values from permutation test of group mean differences (considered significant at $\alpha<0.05$ ).

\begin{tabular}{lrrrrr}
\hline & \multicolumn{1}{l}{ Pan } & \multicolumn{1}{l}{ Gorilla } & \multicolumn{1}{l}{ Pongo } & Homo & Hylobates \\
\hline CR & 0.777 & 0.771 & 0.786 & 0.726 & 0.789 \\
\hline Min & 0.712 & 0.715 & 0.739 & 0.635 & 0.721 \\
Max & 0.894 & 0.867 & 0.886 & 0.892 & 0.891 \\
Median & 0.805 & 0.804 & 0.812 & 0.755 & 0.814 \\
Mean & 0.805 & 0.802 & 0.813 & 0.757 & 0.814 \\
SD & 0.031 & 0.025 & 0.024 & 0.044 & 0.030 \\
\hline Pan & 15 & 14.580 & 0.165 & 0.015 & 0.150 \\
Gorilla & 14.536 & 15 & 0.270 & 0.015 & 0.165 \\
Pongo & 0.120 & 0.240 & 15 & 0.015 & 11.613 \\
Homo & 0.015 & 0.015 & 0.015 & 15 & 0.015 \\
Hylobates & 0.210 & 0.150 & 10.984 & 0.015 & 15 \\
\hline
\end{tabular}


Table 5. Results for the correlation coefficient $(r)$ between the upper and the lower arcade.

\begin{tabular}{l|lll}
\multicolumn{1}{c}{} & PLS1 & PLS2 & PLS3 \\
\hline Pan & 0.757 & 0.841 & 0.858 \\
Gorilla & 0.645 & 0.853 & 0.757 \\
Pongo & 0.728 & 0.851 & 0.828 \\
Homo & 0.695 & 0.664 & 0.668 \\
Hylobates & 0.831 & 0.569 & 0.625 \\
\hline
\end{tabular}


Table 6. Results for the CR and the permutation tests grouped by species and sex (subsample size 15, 1000 resamples) for the upper and the lower arcade. Below, Bonferroni corrected $p$-values from permutation test of sex mean differences (considered significant at $\alpha<0.05$ ).

\begin{tabular}{l|cccccccccc}
\hline & Pan M & Pan F & Gorilla M & Gorilla F & Pongo M & Pongo F & Homo M & Homo $\mathrm{F}$ & Hylo M & Hylo $\mathrm{F}$ \\
\hline $\boldsymbol{C} \boldsymbol{R}$ & 0.837 & 0.831 & 0.720 & 0.809 & 0.771 & 0.834 & 0.756 & 0.859 & 0.836 & 0.795 \\
\hline Min & 0.786 & 0.797 & 0.682 & 0.749 & 0.737 & 0.778 & 0.715 & 0.843 & 0.771 & 0.719 \\
Max & 0.926 & 0.921 & 0.912 & 0.910 & 0.893 & 0.933 & 0.904 & 0.872 & 0.940 & 0.935 \\
Median & 0.847 & 0.872 & 0.804 & 0.840 & 0.809 & 0.858 & 0.793 & 0.864 & 0.862 & 0.844 \\
Mean & 0.853 & 0.869 & 0.803 & 0.839 & 0.810 & 0.857 & 0.796 & 0.862 & 0.861 & 0.842 \\
SD & 0.030 & 0.023 & 0.038 & 0.029 & 0.023 & 0.031 & 0.033 & 0.007 & 0.032 & 0.040 \\
\hline$p$ & 0.950 & \multicolumn{2}{c}{0.002} & 0.002 & 0.002 & 0.214 \\
\hline
\end{tabular}


Table 7. Correlation coefficients ( $r$ ) grouped by species and sex for the upper and the lower arcade.

\begin{tabular}{l|ccc}
\multicolumn{1}{c}{ PLS1 } & PLS2 & PLS3 \\
\hline Pan M & 0.924 & 0.810 & 0.879 \\
Pan F & 0.910 & 0.780 & 0.827 \\
Gorilla M & 0.660 & 0.906 & 0.876 \\
Gorilla F & 0.764 & 0.780 & 0.800 \\
Pongo M & 0.764 & 0.703 & 0.797 \\
Pongo F & 0.852 & 0.784 & 0.705 \\
Homo M & 0.745 & 0.858 & 0.860 \\
Homo F & 0.907 & 0.741 & 0.806 \\
Hylobates M & 0.865 & 0.779 & 0.802 \\
Hylobates F & 0.787 & 0.837 & 0.728 \\
\hline
\end{tabular}


Table 8. Percentage of the total variance explained by size.

\begin{tabular}{lcccc}
\hline & \multicolumn{2}{c}{ Maxillae } & \multicolumn{2}{c}{ Mandibles } \\
\hline Taxon & $\%$ & $p$ & $\%$ & $p$ \\
\hline Pan & 6.80 & $<0.001$ & 4.84 & $<0.001$ \\
Gorilla & 14.25 & $<0.001$ & 8.53 & $<0.001$ \\
Pongo & 12.58 & $<0.001$ & 9.68 & $<0.001$ \\
Homo & 2.49 & $<0.001$ & 2.38 & $<0.004$ \\
Hylobates & 2.36 & $<0.001$ & 3.55 & $<0.001$ \\
Total & 5.38 & $<0.001$ & 8.39 & $<0.001$ \\
\hline
\end{tabular}


Table 9. Percentage of the explained covariance between the premaxilla and the maxilla for the first five PLS components. Symmetrized data; combined PLS: group-mean centered; separate PLS: sex-mean centered.

\begin{tabular}{lc|rrrrr}
\hline & $\begin{array}{c}\text { \% covariance } \\
\text { combined PLS }\end{array}$ & \multicolumn{5}{|c}{ \% covariance separate PLS } \\
\hline & & Pan & Gorilla & Pongo & Homo & Hylobates \\
\hline PLS1 & 84.14 & 44.28 & 85.99 & 67.19 & 79.75 & 74.83 \\
PLS2 & 10.18 & 39.06 & 7.37 & 17.07 & 7.72 & 13.70 \\
PLS3 & 2.20 & 6.44 & 2.21 & 6.47 & 5.41 & 3.95 \\
PLS4 & 1.16 & 3.55 & 1.42 & 3.87 & 2.50 & 3.11 \\
PLS5 & 0.74 & 1.96 & 1.06 & 1.85 & 1.42 & 1.27 \\
\hline
\end{tabular}


Table 10. Results for the CR and the permutation tests between the premaxilla and the maxilla. Subsample size for the permutation is 30.1000 resamples. Below, Bonferroni corrected $p$-values from permutation test of group mean differences (considered significant at $\alpha<0.05$ ).

\begin{tabular}{llllll}
\hline & Pan & Gorilla & Pongo & Homo & Hylobates \\
\hline CR & 0.678 & 0.731 & 0.702 & 0.694 & 0.646 \\
\hline Min & 0.611 & 0.621 & 0.620 & 0.596 & 0.576 \\
Max & 0.803 & 0.882 & 0.844 & 0.834 & 0.809 \\
Median & 0.707 & 0.751 & 0.727 & 0.719 & 0.688 \\
Mean & 0.707 & 0.749 & 0.726 & 0.719 & 0.687 \\
SD & 0.031 & 0.044 & 0.037 & 0.038 & 0.042 \\
\hline Pan & 15 & 0.030 & 8.571 & 5.784 & 0.300 \\
Gorilla & 0.060 & 15 & 0.135 & 0.015 & 0.015 \\
Pongo & 8.796 & 0.120 & 15 & 3.267 & 0.270 \\
Homo & 5.619 & 0.015 & 3.282 & 15 & 2.742 \\
Hylobates & 0.554 & 0.015 & 0.360 & 2.892 & 15 \\
\hline
\end{tabular}


Table 11. Results of the correlation coefficient $(r)$ between the premaxilla and the maxilla.

\begin{tabular}{l|lll}
\multicolumn{2}{c}{ PLS1 } & PLS2 & PLS3 \\
\hline Pan & 0.752 & 0.885 & 0.395 \\
Gorilla & 0.815 & 0.707 & 0.668 \\
Pongo & 0.798 & 0.752 & 0.492 \\
Homo & 0.814 & 0.794 & 0.060 \\
Hylobates & 0.758 & 0.796 & 0.207 \\
\hline
\end{tabular}

